\title{
Valoración de la vulnerabilidad integral en las áreas residenciales de Madrid
}

Rafael R. Temes. Universidad Politécnica de Valencia, Valencia, España.

RESUMEN | La ciudad, en tanto asentamiento eminentemente humano, es reflejo de la diversidad económica, social y cultural de sus habitantes. Como consecuencia de ello, encontramos en un mismo territorio oportunidades distintas, con importantes brechas y fronteras en torno a barrios o ámbitos de características singulares. Partiendo de esta afirmación, se traza como objetivo de este trabajo la definición de un banco de indicadores que permita valorar la vulnerabilidad integral en las áreas residenciales consolidadas del municipio de Madrid. La metodología empleada se basa en el uso de un análisis estadístico multivariable que determina un conjunto de indicadores sintéticos, a partir de los que es posible delimitar los ámbitos de vulnerabilidad integral. De su aplicación se desprende que más del 80 por ciento de los casos así fijados se encuentra fuera de la "almendra central" de Madrid, señalándose la periferia construida entre los años sesenta y setenta como el escenario principal de los problemas urbanos de los próximos años.

PALABRAS CLAVE | vulnerabilidad, segregación, renovación urbana.

ABSTRACT | The city, as an eminently human settlement, is a reflection of the economic, social and cultural diversity of its inhabitants; thus, we can find different kinds of life opportunities within a particular territory. These opportunities, however, are determined or limited by important boundaries related to neighbourhoods or spaces with specific characteristics. From this standpoint, the aim of this work is to define a bank of indicators, which will enable the assessment of integral vulnerability within established residential areas in the municipality of Madrid. The methodology is based on a statistical multivariable analysis in order to determine a set of synthetic indicators that will allow the delimitation of the areas encompassed by vulnerability. After applying it, it is then inferred that more than 80 per cent of the delimited cases are located out of Madrid's 'central almond', which exposes the outskirts of the city built during the sixties and seventies as the main context of integral vulnerability for the next following years.

KEY WORDS | vulnerability, segregation, urban renewal. 


\section{Introducción}

Parece aconsejable recordar de vez en cuando en la disciplina urbanística que la palabra "ciudad" viene del latín civitas, el término con que los romanos llamaban a la ciudadanía. De hecho, la ciudad ha sido tradicionalmente entendida como el lugar de las relaciones sociales, donde la diversidad, densidad y proximidad de las actividades y de las estructuras han permitido a los sujetos la construcción conjunta de la experiencia humana y el acceso directo a la comunicación, al conocimiento y al progreso. Hacer énfasis en la dimensión social de la ciudad es fundamental para entender la amplitud de muchos de los problemas que hoy tenemos en los entornos urbanos, cuyo origen no ha de buscarse únicamente en la forma urbis, sino en la compleja y frágil red de vínculos y relaciones socioeconómicos que realmente moldean la ciudad. Es cierto que los entornos urbanos han sido tradicionalmente los lugares donde mejor se satisfacen las necesidades del hombre; en esencia, la propia acumulación, y las economías de escalas que de ella se derivan, dan pie a tal circunstancia. Pero, a la vez, no es menos cierto que las ciudades han sido el lugar en el que las propias relaciones del hombre han dado forma a una organización social a menudo poco igualitaria, conflictiva y segregadora. De alguna manera, el beneficioso efecto urbano siempre se ha visto oscurecido por la exclusión de grupos con atributos diferenciales.

En los últimos años, la dinámica señalada, lejos de reducirse, no ha hecho más que aumentar en diversas urbes de nuestra realidad más próxima (Ministerio de Fomento, España, s/f). Numerosos autores (Alguacil, 2006; Arrigada \& Rodríguez, 2003; Bruquetas, Moreno \& Walliser, 2005; Egea, Nieto, Domínguez \& González, 2008) coinciden en seńalar cómo se han ido produciendo modificaciones de las estructuras sociales, que han resultado en la emergencia de nuevos colectivos con síntomas de exclusión en varias dimensiones: en el ámbito económico, en el mercado de trabajo y en la vida política y cultural. Dichos colectivos se ven en la obligación de concentrarse en los barrios en declive económico, más degradados social y ambientalmente y con peor calidad en los servicios y equipamientos.

La ciudad del urbanismo funcionalista de mediados del siglo xx, continúa en otras versiones más extendidas y globalizadas sobre el territorio, dando paso a los modelos de ciudad segregada o compartimentada. Para explicar estos fenómenos, la disciplina ha establecido diferentes estructuras, como la dada por Keestelot (2008) en sus definiciones de ciudades topológicas y dramáticas; o la ofrecida por Beck (1998), en la que se introduce una sugerente tipología al hablarnos de "ciudades y", "ciudades ni" y "ciudades o", todas ellas marcando la pauta de lo que, por su parte, Manuel Castell ha dado en llamar "ciudad dual":

La consolidación de la ciudad dual (...) una estructura socioespacial formada por dos sistemas (internamente estratificados), uno de ellos relacionado con el polo dinámico de crecimiento y generación de renta, mientras que el otro concentra la mano de obra degradada en espacios e instituciones que no ofrecen posibilidades de movilidad ascendente en la escala social y que induce a la formación de subculturas de supervivencia y abandono (Castells, 1991, p. 89). 
Ha sido en la primera década del siglo xxi, en el marco de la prosperidad económica que atravesaba el país, cuando en España, y en particular en Madrid, hemos asistido a la sustitución de la población original de los barrios periféricos -que ahora se identifican como barrios desfavorecidos-, por población de origen extranjero, proceso que ha ido dando forma a conglomerados sociales caracterizados por la exclusión y la falta de integración ${ }^{1}$. Dicho fenómeno se ha reproducido con coincidencia espacial en algunas realidades americanas, tanto del norte como latinas, aunque con puntos de partida y matices diferentes. La búsqueda de una mejor "geografía de oportunidad" (Galster \& Killen, 1995) ha producido desplazamientos en los entornos urbanos, dándose fenómenos de sustitución y nueva localización en función de la realidad socioeconómica de cada momento. Este espacio social se ha visto impactado también por otros factores del desfavorecimiento, como pueden ser los relacionados con el acceso a la vivienda, la movilidad (Rodríguez, 2008), el deterioro físico y ambiental, la accesibilidad o el aislamiento, que en su conjunto constituyen un problema integral de múltiples dimensiones. Entre ellas, las condiciones físicas de estas periferias, hoy con cincuenta y sesenta ańos de antigüedad y claros síntomas de obsolescencia, que han sido objeto de atención específica en anteriores estudios (Temes, 2007). Pero no podemos simplificar el problema sin caer en el error de pensar que solo se trata de una cuestión epidérmica de mejora de calles y plazas o del aspecto exterior de los edificios, en la confianza de un "efecto contagio" que en muchas ocasiones no llega nunca a darse. Tomando un interesante trabajo de López de Lucio (2008), a la hora de entender y abordar soluciones frente a la dimensión de estos problemas, debemos pasar del "fachadismo y la renovación del pavimento, a las actuaciones complejas e integrales de la ciudad consolidada" (p. 283). La pregunta, entonces, podría ser: ¿En qué se basan y en qué consisten estas actuaciones complejas?

Fue precisamente esta compleja realidad que caracteriza la ciudad existente, lo que llevó al Área de Gobierno de Urbanismo y Vivienda del Ayuntamiento de Madrid a trazar una serie de líneas estratégicas dentro del Programa Operativo 20072011, centradas en el desarrollo de un modelo de ciudad donde sean sustantivos los principios de calidad y sostenibilidad del medio urbano. La preocupación por identificar y valorar, dentro de la ciudad, áreas con disfunciones o comportamientos problemáticos, ha sido una constante en los trabajos llevados a cabo desde dicha Área. Sin embargo, estos estudios a menudo se han desarrollado de una manera muy sectorial, centrados en aspectos físicos, de gestión o de infraestructuras básicas, orillando la compleja contextualización de la realidad urbana.

1 Las grandes oleadas de llegada de población a Madrid se produjeron entre 1999 y 2007, por lo que la mayor parte de los extranjeros, más del 80 por ciento, lleva más de cinco ańos viviendo en la ciudad. Según la Encuesta de Población Activa, a 1 de enero de 2011, el 37,4 por ciento de los trabajadores desempleados madrileńos son extranjeros; es decir, 89.200 personas (Ayuntamiento de Madrid, 2011). 
A partir de aquí, la administración madrileña, siguiendo los pasos de otras iniciativas urbanas emprendidas en esta misma línea ${ }^{2}$, se propuso establecer una metodología de trabajo para detectar síntomas de vulnerabilidad. Sobre la base de esta exigencia, la Dirección General de Urbanismo del Ayuntamiento de Madrid decidió diseñar un "banco de indicadores" que valorara lo que luego se entenderá como la "vulnerabilidad integral" de la ciudad consolidada. El objetivo marcado desde la Dirección General era definir una sólida estructura de indicadores que permitiese, primero, caracterizar de manera integral la situación de los distintos tejidos residenciales, para luego identificar las situaciones más problemáticas de cara a actuar sobre ellas.

El presente estudio pretende exponer los pasos seguidos para determinar las áreas con un mayor potencial de vulnerabilidad integral detectadas en la ciudad de Madrid. Para ello, el artículo se divide en cuatro partes. Se inicia con una primera revisión del estado del arte en referencia a la vulnerabilidad urbana y la valoración de la exclusión social y residencial (sección "Algunas cuestiones previas..."). Luego, en el apartado "Proceso de operacionalización", se desarrolla un análisis de reducción de la dimensionalidad por componentes principales, con datos centrados fundamentalmente en el año 2009. En una tercera sección se hace un recuento de los resultados obtenidos, y se los compara con otros trabajos de naturaleza similar. Finalmente, se aportan algunas conclusiones sobre los resultados y se apuntan algunas políticas posibles de desarrollar de cara a intentar revertir los problemas detectados. La metodología aplicada en este trabajo es cuantitativa, con uso de fuentes secundarias y empleo del software spss para el tratamiento estadístico, y de ArcGIS para la formación de cartografías.

\section{Algunas cuestiones previas: la definición de vulnerabilidad y áreas de vulnerabilidad integral}

El concepto de vulnerabilidad ha adquirido especial relevancia en las ciencias sociales en los últimos años. Ha sido muy utilizado en el caso de la geografía, referido directamente a las probabilidades de ser afectado negativamente por un fenómeno geográfico y/o climatológico, y también por la economía en relación con la reacción macroeconómica ante el shocks externos (Ffrench-Davis, 1999), si bien en las ciencias sociales ha tenido un auge especial en la última década. Según recoge Rodríguez (2001), dicho impulso parece haberse iniciado con los estudios de Caroline Moser y su grupo en el Banco Mundial, sintetizados en el denominado asset/vulnerability framework (Moser \& Van Bronkhorst 1999; Kaztman, Beccaria, Filgueira, Gobert \& Kessler, 1999).

Entre ellas debemos citar la Ley 2/2004, de 4 de junio, de mejora de barrios, áreas urbanas y villas que requieren una atención especial de Cataluña (Generalidad de Cataluña, 2004); el Programa Izartu de Cohesión Territorial del País Vasco (Gobierno Vasco, 2001); el Plan de Rehabilitación Integral de Castilla y León (Dirección General de Vivienda, Arquitectura y Urbanismo, Junta de Castilla y León, 2012); y Programa de Recuperación de Barrios (Ministerio de Vivienda y Urbanismo, Chile, 2012). 
Ahora bien, siempre según Rodríguez (2001), la noción de vulnerabilidad ha superado ampliamente esta delimitación inicial, habiéndose empleado como un componente de creciente importancia dentro del complejo de desventajas sociales y demográficas que se delinean en la "modernidad tardía". Se ha considerado como el rasgo negativo más relevante del modelo de desarrollo basado en la liberalización económica y la apertura comercial (Comisión Económica para América Latina y el Caribe [Cepal], 2000; Pizarro, 2001). Se ha planteado que es la manifestación más clara de la carencia de poder que experimentan grupos específicos, pero cuantiosos, de la humanidad (Bustamante, 2000). Se ha sostenido que es el reflejo de la gran cantidad de movimientos de entrada y salida a la condición de pobreza (Cepal, 2000).

Este trabajo utiliza la noción de vulnerabilidad de manera amplia e integral. En palabras de Alguacil (2006), entenderemos la vulnerabilidad como un:

Término que se refiere a la movilidad social descendente y que viene a significarse como la antesala o caída en la exclusión social y residencial. Con frecuencia se suele referir tanto a colectivos sociales como a territorios o lugares en situación de riesgo o de declive, aunando por tanto el doble vínculo entre espacio y estructura social (p. 161).

De acuerdo con esta conceptualización y acotando el territorio de análisis en lo urbano, debemos definir qué entendemos por exclusión o segregación social y residencial, antecedentes de la vulnerabilidad urbana.

\section{Exclusión social}

Siempre siguiendo a Alguacil (2006), entendemos por exclusión social aquel proceso de malestar producido por la combinación de múltiples dimensiones de desventaja en el que toda esperanza de movilidad social ascendente, de superación de la condición social de exclusión o próxima a ella, es contemplada como extremadamente difícil de alcanzar. La acompaña una percepción de inseguridad y de miedo a la posibilidad de movilidad social descendente, de empeoramiento de las condiciones de vida actuales. Como señala el mismo autor:

La exclusión social es expresar que el problema no es ya solamente el de desigualdades entre la parte alta y la parte baja de la escala social, sino también el de la distancia, en el cuerpo social, entre los que participan en su dinámica y los que son rechazados hacia sus márgenes (Alguacil, 2006, p. 106).

\section{Exclusión residencial}

En España no existe una tradición sostenida de estudios de exclusión residencial ${ }^{3}$. Por su parte, como apunta Molinatti (2013), en América Latina estos estudios son también recientes. Centrados por lo general en la dimensión socioeconómica de la segregación ${ }^{4}$, consideran que las fuertes desigualdades sociales, de ingreso y de clase social representan la característica más sobresaliente de la estructura social latinoamericana. Sin embargo, autores como Rodríguez y Arriagada (2004) y

3 Algunos antecedentes pueden ser Cortés (1997), Arias (2000), Mayeur (1998).

4 Dando paso al concepto de segregación residencial socioeconómica (sRs). 
Sabatini, Cáceres y Cerda (2001) destacan que la investigación empírica sobre la magnitud y la evolución de la segregación residencial socioeconómica (SRS) para la región latinoamericana es escasa, fragmentaria y poco comparable entre países. Pese a lo anterior, debemos recordar que el concepto no es en absoluto reciente. La exclusión residencial puede definirse como un proceso complejo y en continua evolución, que implica la incapacidad estructural de algunos grupos e individuos para resolver sus necesidades de alojamiento (Antón, Cortés, Martínez \& Navarrete, 2008).

A partir de estas definiciones, la "vulnerabilidad urbana" se entenderá como aquella situación existente en ciudades donde coinciden situaciones de exclusión residencial y exclusión social. En definitiva, las áreas vulnerables urbanas no son otra cosa que la expresión de una producción social del espacio que se origina en un contexto general de desigualdad social (Alguacil, 2006).

Ahora bien, la espacialidad o proyección sobre un entorno urbano de la definición de vulnerabilidad no está exenta de nociones de cierta ambigüedad, que con frecuencia desperfilan la precisión del concepto. En muchas ocasiones, se detecta también superposición y duplicidad de contenidos que no justifican el empleo de términos diferentes. Con frecuencia, las traducciones de otras lenguas o la extrapolación de términos afines desde otras disciplinas, contribuyen a aumentar la confusión entre denominaciones, haciéndose necesaria una labor de acotación inicial. Sirvan, por tanto, los siguientes puntos como aclaración introductoria de conceptos y de elección de la terminología que consideramos más apropiada para el análisis desarrollado.

\section{Áreas de atención especial}

Esta expresión aparece en el panorama nacional por vez primera en 2004, a raíz de la Ley de mejora de barrios, áreas urbanas y villas que requieren una atención especial de Cataluña (Parlamento de Cataluña, 2004). En su preámbulo, se justifica esta ley por detectarse, a lo largo de la geografía catalana, muchas áreas que por razón de las condiciones históricas en las que fueron creadas y desarrolladas, sufren importantes problemas urbanísticos y sociales que, en ocasiones, lejos de resolverse, tienden a agravarse con el tiempo. Entre dichos espacios destacan algunos donde se concentran procesos de deterioro urbano, problemas demográficos (causados por la pérdida o el excesivo crecimiento de la población) y carencias económicas y sociales. Son, en muchos casos, barrios viejos o cascos antiguos, extensiones suburbanas realizadas sin una planificación ni dotación de equipamientos apropiados, polígonos de viviendas o áreas de urbanización marginal. La "atención especial" hace referencia a la superación de las intervenciones meramente sectoriales y a las iniciativas que permitan emprender acciones de carácter integral, dirigidas tanto a la rehabilitación física como a la sostenibilidad ambiental, el bienestar social y la dinamización económica.

\section{Áreas sensibles}

En este caso hacemos referencia a una expresión derivada fundamentalmente de la cultura francesa, en la que desde hace varias décadas se enfrentan problemas de segregación y marginalidad especialmente agudos en les banlieues ${ }^{5}$. En la mayoría de

Término con el cual se denominan los suburbios de las grandes ciudades francesas. 
los casos, los escenarios en los que trascurren estos incidentes son grands ensembles, construidos de una sola vez entre los ańos cincuenta y sesenta, que se deterioran en su parte física, pero que también son objeto de importantes desequilibrios económicos y sociales. Este es el origen, en Francia, de lo que luego se denominará como Zones Urbaines Sensibles (Zonas Urbanas Sensibles, zus). Las zus quedan definidas en el apartado 3 del artículo 42 de la Ley 95-115 del 4 de febrero de 1995, de orientación para la organización y el desarrollo del territorio (République Française, 1995). Se caracterizan "por la presencia de grandes conjuntos o barrios de viviendas deterioradas y por un desequilibrio acentuado entre la vivienda y el empleo. Estas zonas incluyen lo que se denominará como Zonas de reactivación urbana y Zonas francas urbanas". La selección de las más de 750 zus de Francia, que albergan una población superior a los 4 millones de habitantes, se ha basado en criterios tanto de deterioro físico de los conjuntos urbanos, como de desequilibrio económico y social de las comunidades integrantes.

\section{Áreas en deterioro, degradación o declive}

En la mayor parte de la bibliografía consultada, en la que se trata a la ciudad y sus edificios con una visión plenamente consciente de su duración limitada, se utilizan como sinónimos las expresiones: "deterioro, degradación ${ }^{6}$, declive". Todos estos sustantivos tienen un factor común: subrayan un proceso que se está dando en un área determinada y que tiene una clara dirección negativa en cuanto a pérdida de capacidades. Tanto en su referencia más amplia para la ciudad, o más concreta para un edificio, entenderemos como "deterioro, degradación o declive", la pérdida de capacidad consecuencia del paso del tiempo o de la falta de mantenimiento, o resultado de una combinación de factores externos. En definitiva, estos términos funcionan habitualmente como sinónimos y aluden igualmente a una situación integral de decaimiento.

\section{Áreas en crisis o en dificultades}

Esta expresión deriva de la traducción del término Quartiers en crise, nombre de una de las redes más consolidadas en el sector de la regeneración urbana de Europa. Quartiers en Crise - Red Europea para la Regeneración Territorial (QeC-ERAN), ha desempeñado un papel estratégico en el desarrollo de programas asociados con los fondos estructurales y de cohesión. De hecho, dicha Red ha llevado a cabo los estudios iniciales y la realización de pruebas piloto relacionadas directamente con la creación del programa Urban, iniciativa orientada a favorecer el desarrollo sostenible de las ciudades y barrios en crisis de la Unión Europea. Dieciocho años después, es uno de los actores clave de Urbact, programa de intercambio de experiencias entre ciudades europeas y de difusión de conocimientos sobre el desarrollo urbano, que trata de rentabilizar la buena práctica generada por el programa Urban. En la traducción al castellano de quartiers en crise, es frecuente evitar la literalidad y

6 El Decreto 236/2000, de 28 de noviembre, por el que se establecen medidas de apoyo a actuaciones integrales de revitalización urbana en la Comunidad Autónoma del País Vasco, define por vez primera en la legislación española el significado de "las áreas urbanas degradadas". Véase Gobierno Vasco, Departamento de Hacienda y Administración Pública (2000). 
emplear "barrios en dificultades". Nuevamente, nos encontramos con expresiones que no albergan ninguna diferencia con las expuestas con anterioridad, si bien en este caso es más frecuente su uso en textos y documentos relacionados con las iniciativas urbanas europeas.

\section{Áreas desfavorecidas}

Si por "vulnerabilidad" entendemos el conjunto de circunstancias (ambientales, sociales, económicas y políticas) que potencian la exclusión social y que dificultan la regeneración de determinadas áreas urbanas al desalentar la inversión y la creación de empleo, y facilitar la marginación de determinados colectivos, el "desfavorecimiento" sería la materialización de dicho riesgo en una situación de exclusión ya consolidada. En este sentido, podemos adoptar la definición de desfavorecimiento como "una situación compleja de carencia de recursos que impide disfrutar de una calidad de vida que la sociedad considera adecuada en la actualidad" (Arias, 2000, p. 10). La expresión "áreas desfavorecidas" (distressed urban areas) ha tenido especial repercusión, sobre todo, a raíz de la participación de Espańa en el proyecto de la Organización para la Cooperación y Desarrollo Económicos (OCDE), Project Group on Distressed Urban Areas, a mediados de los noventa, en el que se presentaba una aproximación a las desigualdades presentes en determinadas áreas de las ciudades espańolas.

\section{Áreas vulnerables}

Desde nuestro punto de vista, esta es la denominación más correcta -además de la más aceptada- para referirse a las áreas de ciudad caracterizadas por la presencia de indicadores sociales, urbanos y económicos claramente regresivos. La Organización de las Naciones Unidas (2004), a través de su Departamento de Asuntos Económicos y Sociales, ofrece la siguiente definición del concepto "vulnerabilidad":

En esencia, la vulnerabilidad puede definirse como un estado de elevada exposición a determinados riesgos e incertidumbres, combinado con una capacidad disminuida para protegerse o defenderse de ellos y hacer frente a sus consecuencias negativas. La vulnerabilidad existe en todos los niveles y dimensiones de la sociedad y es parte integrante de la condición humana, por lo que afecta tanto a cada persona como a la sociedad en su totalidad (p. $8, \S 48$ ).

A partir de esta definición, como ya hemos dado constancia antes, Alguacil (2011) determina que la vulnerabilidad urbana está apoyada en dos conceptos trascendentales e íntimamente relacionados: exclusión social y exclusión residencial.

Tras el repaso de los términos más utilizados para referirse a estos tipos de áreas, podemos concluir en varias ideas:

- La diferencia entre los contenidos de cada una de las denominaciones descritas es prácticamente imperceptible, justificando su adjetivación únicamente por la fuente u origen de donde se derivan.

- En todos los casos, la denominación de dichas áreas hace alusión a situaciones provocadas como consecuencia de la combinación de factores físico-urbanos, sociales y económicos, describiéndose la dinámica de su comportamiento a partir 
de lo que hemos dado en llamar "la espiral de la obsolescencia", es decir, "el proceso de degradación va aumentando progresivamente a medida que se van incorporando y entrando en sintonía cada uno de los factores anteriores citados" (Temes, 2007, p. 53).

- Finalmente, la expresión que consideramos más adecuada, por su empleo en el campo de las ciencias sociales, como el urbanismo, y la que va a ser empleada en este artículo, es "áreas vulnerables".

Una vez acotada nuestra definición de áreas vulnerables, podemos dar paso a la definición de las distintas tipologías de vulnerabilidad que utilizaremos en este trabajo.

Hablaremos de "monovulnerabilidad", en aquellas áreas en las que solo se identifica un tipo de vulnerabilidad: social, económica o residencial.

Hablaremos de "polivulnerabilidad", en aquellas áreas en las que es posible identificar dos tipos de vulnerabilidad que se dan simultáneamente: vulnerabilidad residencial + económica; vulnerabilidad económica + social; vulnerabilidad social + residencial.

Por último, hablaremos de "vulnerabilidad integral" en aquellas áreas en las que es posible identificar tres tipos de vulnerabilidad simultáneas: social + económica + residencial. Un área urbana con vulnerabilidad integral es aquella en la que se recogen las temáticas ambientales, sociales, físicas y económicas que, de forma interrelacionada y diacrónica, se materializan en la obsolescencia urbana, la escasez de inversiones, las altas tasas de desempleo, los claros síntomas de marginación social, así como una generalizada situación de precariedad. Para su determinación, será por tanto necesario un método de análisis que permita valorar todas las dimensiones que concurren en dicho concepto. A ello nos dedicaremos en los siguientes apartados.

\section{Proceso de operacionalización}

El hecho social deja de ser una mera observación para pasar a ser objeto de investigación en virtud del proceso de operacionalización al que se lo somete, definido como aquel en el cual una idea general se transcribe a lenguaje científico (De Miguel, 1967). El concepto (variable teórica) o las dimensiones del concepto (variables teóricas), para poder ser medibles, se operacionalizan. Así, cuando a las variables teóricas de un hecho o fenómeno se les aplica mediciones empíricas, se convierten en variables prácticas o, lo que es lo mismo, en un "indicador" (De Miguel \& Sevilla-Guzmán, 1973). Definimos, pues, indicador como la medición operativa de las dimensiones de un concepto dado. Cada una de estas medidas constituye un indicador del concepto que quieren medir.

A partir de estos antecedentes y con la finalidad de diseñar una batería de indicadores que permitiera una adecuada identificación de las áreas de vulnerabilidad integral de Madrid, se procedió a establecer los siguientes criterios básicos para su definición:

- Integralidad. Condición en la que ya nos hemos extendido, y que garantiza la valoración de las áreas urbanas desde una perspectiva social, económica y física de los espacios urbanos. 
- Representatividad. En cuanto a que los datos empleados para el diseño del banco de indicadores debían de ser los más actuales posibles y abarcar de forma homogénea la totalidad de los ámbitos de análisis.

- Renovación. En referencia a la vocación, establecida como condición inicial en el trabajo, de revisión temporal del banco de indicadores para mantener un seguimiento de la dinámica de las áreas, en función de las medidas adoptadas. Las fuentes de trabajo debían, por tanto, ser propias del Ayuntamiento o de acceso directo para el mismo.

- Sistematización. Haciendo alusión a la conveniencia de trabajar a través de un SIG (Sistema de Información Geográfica), que pudiera no solo mantener siempre vinculada la información alfanumérica con la gráfica a través de una estructura sólida, sino que, además, permitiese una fácil actualización de los datos en todo momento.

\section{Encuadre cronológico y territorial de referencia}

La delimitación del entorno en el que se produce un fenómeno urbano cualquiera es, casi siempre, un asunto que suscita dudas y controversias. En nuestro caso, la decisión del encuadre básico que toma a la ciudad de Madrid como objeto de análisis, se despeja desde el comienzo por parte de la administración que encarga la realización del trabajo. Es cierto que se analiza un fenómeno que no reside exclusivamente en el término municipal de Madrid. Asumiendo la fragilidad de dicha delimitación en un área en la que se ha demostrado repetidas veces la fortaleza creciente de sus interrelaciones, el límite administrativo nos permite trabajar de forma sistemática con la información recogida de diversas fuentes: datos catastrales, padrón de habitantes, información estadística del Ayuntamiento, etcétera. De esta manera asumimos desde un principio dicha limitación como condición del propio análisis.

Por su parte, la unidad mínima territorial de referencia física en el trabajo ha sido la sección censal, entidad para la que es posible obtener información estadística desagregada. Las secciones son áreas, adecuadamente delimitadas, que dividen todo el territorio municipal evitando solapamientos y zonas no recogidas ${ }^{7}$. Ahora bien, el seccionado censal atiende directamente a criterios de dinámica demográfica que hacen dicha división, para nuestros propósitos, doblemente frágil. Por un lado, esta dependencia demográfica impide una delimitación fija de las secciones año tras año, dificultando enormemente la serialización de datos y la comparación entre ellos. Por su parte, las divisiones censales no atienden a criterios morfológicos que dotarían de mayor coherencia a las áreas estudiadas. Para ambos problemas hemos intentado dar una solución mediante una secuencia de geoprocesamientos encadenados que actualizan las secciones y a través de una redelimitación de agrupaciones censales con criterios morfológicos. Más adelante daremos cuenta de ello.

7 El seccionado censal está regulado por la Ley Orgánica 5/85 sobre Régimen Electoral, que establece un tamaño medio de entre 500 y 2.000 electores, salvo en los municipios de sección única (Junta Electoral Central, España, 2012). 


\section{Fuentes estadísticas y gráficas utilizadas}

Dadas las características de la información y los componentes de la vulnerabilidad urbana, se trabajará con índices sintéticos basados en el uso de fuentes secundarias. Aquí consideraremos como datos secundarios aquellos que han sido generados de manera independiente y con objetivos diferentes a los de la investigación en curso (Márquez, 2006).

Ya hemos comentado, en los puntos anteriores, la preocupación en este estudio por trabajar con datos actualizados, adecuadamente armonizados y de fácil acceso para la administración local. De esta manera, se descartó desde el comienzo el uso del Censo 2001 (Instituto Nacional de Estadística, España, 2001), y se procedió a realizar un primer esfuerzo de coordinación entre diferentes áreas del Ayuntamiento de Madrid. A pesar de contar esta administración con una bien gestionada Dirección General de Estadística, en la que se reúnen, compilan y explotan buena parte de los datos de interés municipal, tanto por la naturaleza y diversidad de la información que se requería, como por la escala de agregación de los mismos, hubo que proceder a recopilar las fuentes más adecuadas. Esta selección estuvo presidida siempre por el principio básico de confiabilidad de la fuente y posibilidad de reproducción futura. Así, en esta primera fase, se tomó la precaución de identificar los metadatos necesarios tanto para facilitar, en posteriores ocasiones, la repetición de las solicitudes, como para controlar el origen de las fuentes. Esta cuestión se tuvo especialmente en cuenta de cara a su compatibilidad histórica posterior. La fecha de referencia general utilizada fue el año 2009, si bien, como podemos apreciar en la relación siguiente, figuran también datos de 2007 y 2008 (Cuadro 1).

\section{CUADro 1 Fuentes de información estadística}

\begin{tabular}{|c|}
\hline RELACIÓN DE FUENTES \\
\hline Padrón Municipal de Habitantes a 1 de enero de 2009. Servicio de Estadística del Ayuntamiento de Madrid. \\
\hline $\begin{array}{l}\text { Paro registrado según el Instituto Nacional de Empleo (INEM) a fecha } 1 \text { de enero de 2009. Servicio de } \\
\text { Estadística del Ayuntamiento de Madrid. }\end{array}$ \\
\hline $\begin{array}{l}\text { Población activa estimada a partir de la información conocida. Los últimos datos son los derivados del } \\
\text { Censo de Población y Viviendas de } 2001 .\end{array}$ \\
\hline $\begin{array}{l}\text { Afiliados en empresas de la ciudad de Madrid a } 1 \text { de enero de 2009. Fichero General de Afiliación } \\
\text { de la Tesorería General de la Seguridad Social (Ministerio de Trabajo y Asuntos Sociales). Servicio de } \\
\text { Estadística del Ayuntamiento de Madrid. }\end{array}$ \\
\hline $\begin{array}{l}\text { Directorio de Unidades de Actividad Económica de la Comunidad de Madrid, 2007. Dirección } \\
\text { General de Economía, Estadística e Innovación Tecnológica. Consejería de Economía y Hacienda. }\end{array}$ \\
\hline $\begin{array}{l}\text { Base de datos catastral para el municipio de Madrid a fecha de noviembre de 2007. Dirección General } \\
\text { del Catastro. Agencia Tributaria Municipal. }\end{array}$ \\
\hline $\begin{array}{l}\text { Base de datos de las Inspecciones Técnicas de Edificios (ITE) de Madrid con fecha diciembre } 2008 . \\
\text { Dirección General de Ejecución y Control de la Edificación. }\end{array}$ \\
\hline $\begin{array}{l}\text { Nivel de Ruido Continuo Equivalente Diurno (Ld). Mapa Estratégico de Ruido de Madrid 2006, aprobado } \\
\text { en enero de 2009. Área de Gobierno de Medio Ambiente y Movilidad. Departamento de Control Acústico. }\end{array}$ \\
\hline $\begin{array}{l}\text { Distribución de paradas, estaciones y rutas de transportes públicos de Madrid con fecha } 2008 . \\
\text { Consorcio de Transportes de Madrid. }\end{array}$ \\
\hline
\end{tabular}

FUENTE ELABORACIÓN PROPIA 


\section{Determinación de las variables básicas del estudio}

Una vez identificadas las dimensiones que representan el concepto, hay que seleccionar los indicadores de las dimensiones descritas que permiten su cuantificación. Evidentemente, al tener que elegir un número de indicadores, perdemos matices del concepto, pero ganamos la posibilidad de medición. El proceso de selección de las variables y transformación de las mismas en indicadores simples y complejos supuso una fase fundamental del análisis y se llevó a cabo mediante un grupo de trabajo multidisciplinar, compuesto por diferentes técnicos del Área de Gobierno de Urbanismo y Vivienda. Aunque en la disciplina no existe consenso sobre la determinación de las variables para el análisis de la vulnerabilidad integral, las que finalmente hemos adoptado no difieren mucho de las que se han utilizado en estudios similares realizados por diversos autores, como Conway y Konvitz (2000), Subirats y Gomà (2003), Hernández Aja (2007), Ministerio de Fomento \& Instituto Juan de Herrera (2010), Pérez (2007), Egea et al. (2008), Antón et al. (2008), para otros ámbitos geográficos o a otras escalas de análisis. En el Cuadro 2 mostramos el conjunto de variables empleado finalmente en el trabajo en comparación con dos de las referencias principales utilizadas. 


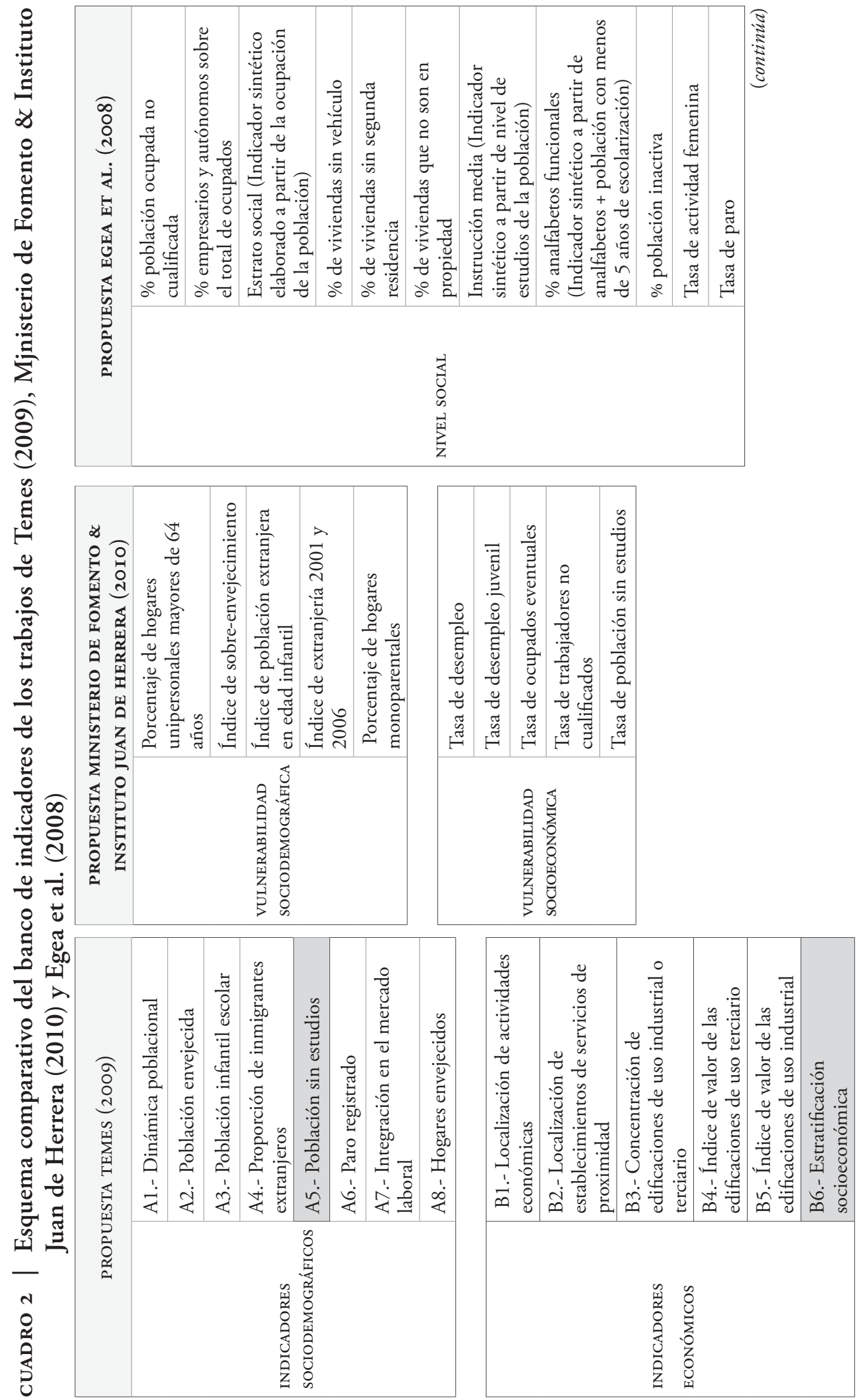



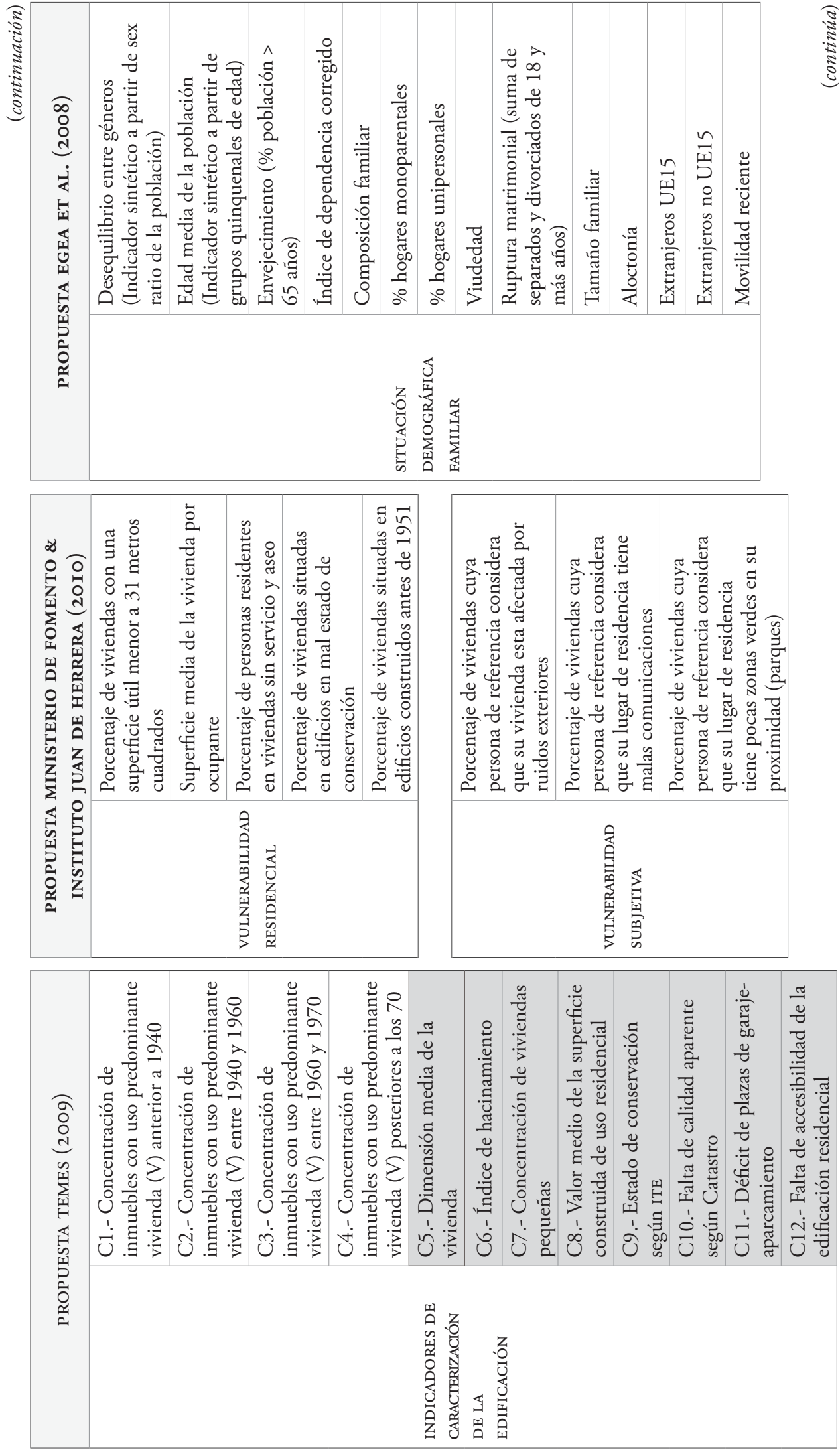

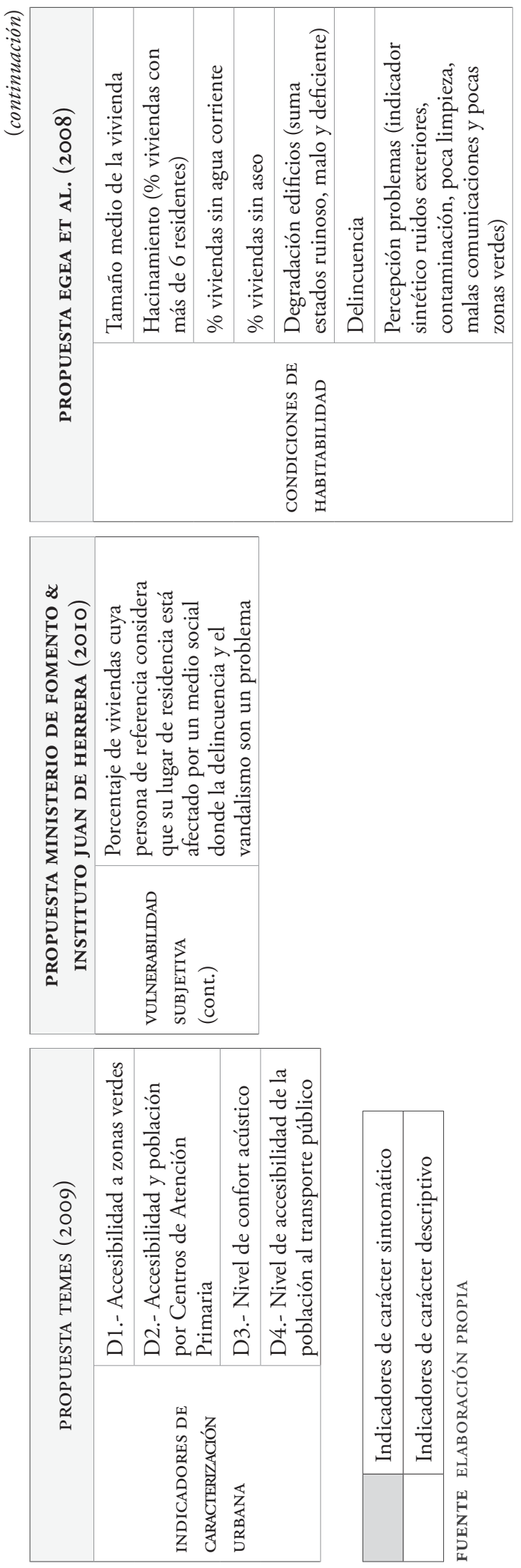
La batería de treinta indicadores adoptada se agrupó en cuatro categorías, cuya denominación y descripción básica fue la siguiente:

a. Indicadores sociodemográficos. Los procesos de segregación social se basan no solo en la pertenencia a una clase social determinada, sino también en otros factores, como la edad, dependencia, estado civil, religión, etnia, procedencia, etcétera. A menudo se afirma que los edificios envejecen con sus habitantes, siendo significativa la correlación entre inmuebles envejecidos y edad de sus residentes. Por otro lado, la concentración de población inmigrante, acompañada con una baja capacitación laboral y escasa integración en el mercado de trabajo, marca en Madrid, como en muchas otras ciudades, claras "islas urbanas" en las que se territorializa la segregación. Para el establecimiento de estos indicadores se han tenido especialmente en cuenta los trabajos de Rodríguez (2001).

b. Indicadores de localización de la actividad económica. Cada espacio de la ciudad adquiere un valor simbólico de prestigio y estatus que se transmite a sus residentes, y que acaba marcando los precios del suelo y la vivienda, así como de las actividades allí desarrolladas. La brecha social y económica se territorializa en la ciudad, manifestándose en ocasiones de forma especialmente clara. En Madrid, la "línea de la pobreza", denominada así por el demógrafo Montoliu (2008), establece una frontera que divide la ciudad y su entorno metropolitano en dos territorios, norte y sur, social y económicamente diferentes. Se trata de una frontera que sobrevive de forma crónica y persistente a través del tiempo, y que se confirma con otros recientes trabajos, como el proyecto Medea ${ }^{8}$.

c. Indicadores de características de la edificación residencial. No supone una novedad destacar la influencia que ejercen las condiciones de habitabilidad en los tejidos urbanos y los componentes sociodemográficos de la población que se ubica en ellos. Podemos hablar de un primer desencuentro entre hábitat y habitantes como consecuencia del deterioro de las condiciones de la vivienda, que puede desencadenar una situación de segregación urbana y producir el conocido fenómeno de "invasión-sucesión", ampliamente estudiado por la Escuela de Chicago. A dicha situación se le unen procesos de hacinamiento, incorporación al mercado de pisos sin condiciones, alquileres abusivos, etcétera.

d. Indicadores de características urbanas. La propia configuración urbana influye directamente en la construcción de la imagen de calidad o declive de los barrios. Más allá de la percepción de zonas carentes de equipamientos y servicios o del análisis de estándares, la valoración de la accesibilidad a los espacios y dotaciones colectivas permite relacionar a usuarios y servicios, pudiendo medirse de forma objetiva el nivel de alcance real para la población.

Del conjunto de indicadores seleccionados, se decidió constituir dos grupos, atendiendo al grado de representatividad y significación que cada uno de ellos podía aportar. Los "Indicadores de carácter sintomático" se definieron como aquellos indicadores que, ampliamente contrastados también por otros estudios, podían

8 En el proyecto Medea se analiza un indicador compuesto formado a partir de cinco variables sociodemográficas, obtenidas del Censo de 2001: porcentajes de desempleados, de trabajadores temporales, de trabajadores manuales y con nivel educativo bajo (>16 ańos y 16-29 años). Consultado en http://www.proyectomedea.org/ 
considerarse como identificativos de la vulnerabilidad integral. Por su parte, los "Indicadores de carácter descriptivo" se definieron como aquellos que iban a permitir matizar o completar la selección de áreas vulnerables, si bien por sí solos no aportaban criterios objetivos para señalar la vulnerabilidad.

\section{Algunos comentarios sobre los indicadores de carácter sintomático}

Creemos útil describir algunos de los indicadores sintomáticos empleados, por su clara influencia posterior en el resultado de las áreas identificadas. Con el indicador "Hogares envejecidos" se sintetiza una valoración de doble dimensión, que afecta no solo a la edad de los residentes, sino también a la geometría o agrupación de los mismos en hogares, los que pueden aproximarse, en cierta medida, a lo que serían viviendas. Así, al analizar la proporción sobre el total de hogares de la suma de los que entendemos como envejecidos - es decir, los formados por: 'Una mujer sola de 65 o más años', 'Un hombre solo de 65 o más años' y 'Dos adultos, uno al menos de 65 o más años, sin menores'-, nos encontramos con que más del 25 por ciento de los hogares de Madrid pueden considerase como envejecidos. Además, su distribución es especialmente significativa (Figura 1). Se produce una clara concentración en la periferia, en barrios como Orcasitas, Fontarrón, Vianteros Águilas, Hellin, Rejas, Amposta y Valdezarzas; y, sin embargo, la media en el distrito Centro es de 19,9 por ciento. Claramente el centro ya no acoge a la población más envejecida de la capital, situándose su proporción de envejecimiento por debajo de la media municipal ${ }^{10}$ (Figura 1).

Por su parte, los indicadores de "Paro registrado" y "Población sin estudios" confirman una clara correlación entre ellos, manifestando, además, en el caso de Madrid, una evidente concentración en el sur, sobre todo en los distritos de Villaverde, Puente de Vallecas, Usera y San Blas.

Por otro lado, el índice que mide la proporción de inmigrantes extranjeros ${ }^{11}$ nos muestra un reparto desigual entre los diferentes distritos. Al menos en cada uno de ellos existe un 10 por ciento de esa categoría poblacional, estableciéndose la media en un 12,7 por ciento, si bien hay distritos con concentraciones significativamente mayores, como son el Centro, Carabanchel, Usera, Puente de Vallecas o Tetuán. En muchos de ellos, como ya comentamos antes, son coincidentes también las mayores proporciones de paro y de población sin formación. Lo más destacable de la representación gráfica de este indicador es la formación de claros "nichos urbanos" de concentración de inmigrantes extranjeros en torno a los barrios de San Diego, Embajadores, Chopera, San Cristóbal, Bellas Vistas y Almendrales, entre otros. Es significativa la correlación que se produce entre estos ámbitos y el indicador "Falta de calidad aparente en la edificación según Catastro”, también tratado en este trabajo.

9 La propuesta y la definición de este indicador, ya utilizado para otros trabajos, corresponden al demógrafo Enrique Montoliu. Departamento de Datos Estadísticos. Estadísticas Sociales y Demográficas. Ayuntamiento de Madrid.

10 Media municipal en 25,89.

11 Entendiendo por población inmigrante extranjera la de nacionalidad diferente a la de la Unión Europea (15) + Unión Europea (15-25) y otros países de la OCDE. 
FIgURA 1 | Indicador A8 Hogares envejecidos

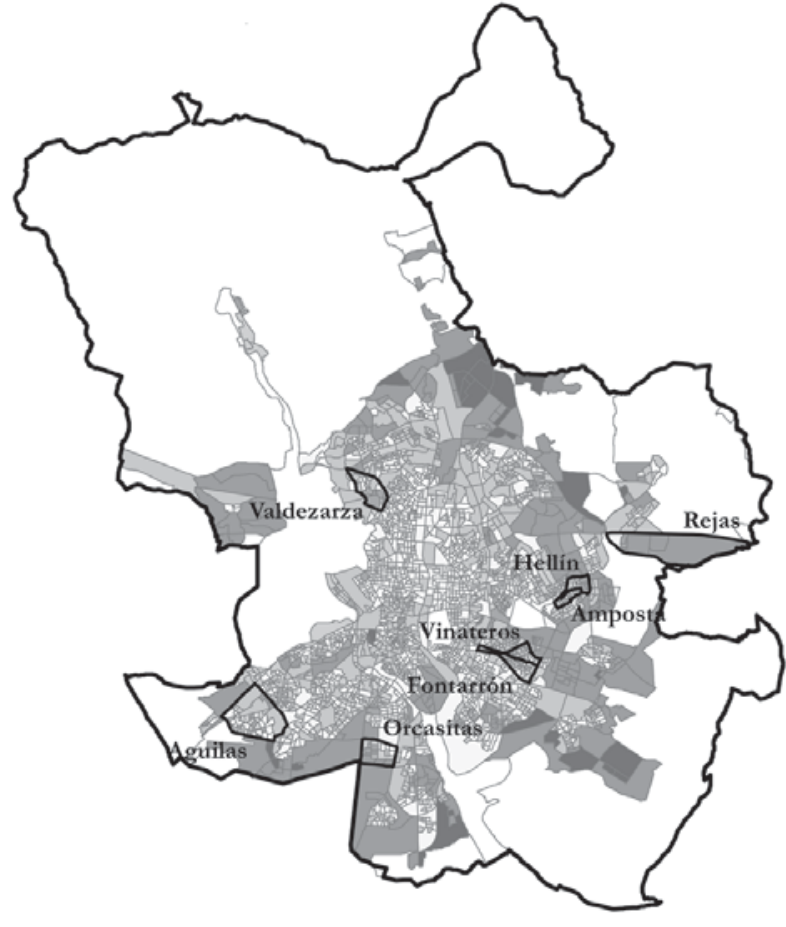

Leyenda
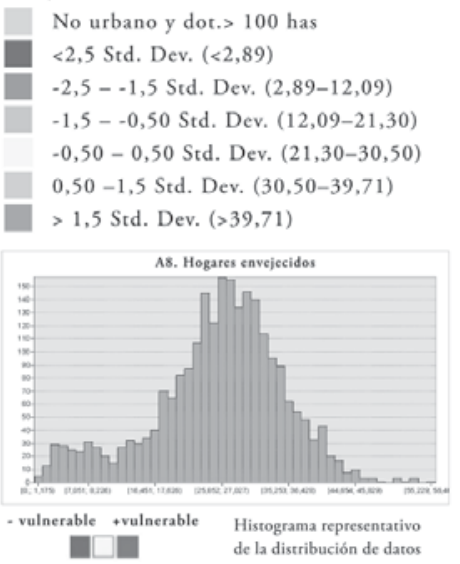

Definición: Porcentaje de hogares envejecidos sobre el total de hogares

Fórmula: HEnv* 100/HT

HEnv $=$ Suma de hogares donde se dé: 'Una mujer sola de 65 o más años', Un hombre solo de 65 o más años' y 'Dos adultos, uno al menos de 65 o más años, sin menores' $\mathrm{HT}=$ Total de hogares

Fuente: Padrón Municipal 2009, Ayuntamiento de Madrid

FUENTE ELABORACIÓN PROPIA

En lo que respecta a las variables que miden la actividad económica de la ciudad, destacamos el indicador "Estratificación socioeconómica" utilizado. En la Comunidad de Madrid, ya se ha demostrado la correlación significativa entre las condiciones de los colectivos de población ocupada y el nivel de rentas de las mismas, siendo representativa del nivel de ingresos de la población (Moreno, 2003). Como este mismo autor afirma:

La tríada de atributos personales, ocupación-estudios-renta, indisolublemente entrelazados por nexos de causalidades mutuas, confieren al individuo un determinado estatus socioeconómico que, a su vez, le coloca en una concreta posición ante el mercado de la vivienda. Ello conduce a unas posibilidades de elección de lugar de residencia muy desiguales socialmente, como es bien conocido (p. 59).

Para el caso del municipio de Madrid, es clara la división a través de la ya mencionada "línea de pobreza", que segrega rentas del norte al sur apoyándose aproximadamente en la traza formada por el Paseo de Extremadura, sur de la M30, avenida de América y Aragón. Solo algunos reductos en el distrito Centro (Barrio de Embajadores) o en los distritos de Tetuán y Chamberí marcan algunas diferencias.

En lo referente a los indicadores sintomáticos de las características residenciales, factores como el tamańo medio de las viviendas, la falta de calidad aparente y la carencia de accesibilidad a las viviendas, manifiestan de forma contundente áreas en las que se concentra un parque edificado obsoleto desde el punto de vista 
funcional. Estas áreas, además, están altamente correlacionadas con la edificación construida entre las décadas de los sesenta y setenta, intervalo de veinte años como ya vimos- en el que se produjo el mayor crecimiento de vivienda en Madrid y en España hasta la fecha conocido.

\section{Síntesis de indicadores. La reducción de la dimensionalidad}

Son numerosas las técnicas habitualmente empleadas en trabajos de similar naturaleza a los nuestros, para reducir el número de variables a aquellas que sean significativas del problema. Algunos de los procedimientos más utilizados en estos estudios son el análisis de varianza, factorial, de componentes principales, así como la combinación entre ellos. En particular, el análisis factorial es una técnica multivariable que tiene por cometido reducir un conjunto de $v$ variables aleatorias (interrelacionadas), en un grupo de $f$ factores latentes (independientes), de tal manera que $f$ factores siempre serán, en número, inferiores a las $v$ variables iniciales. Los factores reflejan la síntesis de la información redundante de las variables. En última instancia, el éxito de esta técnica viene dado en la medida en que su resolución cumpla dos requisitos básicos (Bisquerra, 1989): i) el principio de parsimonia, común a toda la teoría científica, que establece que "todo modelo debe ser más simple que los datos en los que se basa” (King, Keohane \& Verba, 2000, p. 15); y ii) el principio según el cual los factores elegidos deben ser interpretables.

En este caso, y si cada una de las variables es susceptible de ser expresada a partir de una serie de factores latentes desconocidos, estos factores, a su vez, pueden ser considerados como indicadores nuevos, indicadores sintéticos, los cuales resumen el conjunto de información proporcionada por los indicadores originales. La validez de todo el proceso metodológico asociado al análisis factorial solo se garantiza si se siguen dos pasos previos:

- Análisis exploratorio de los datos. Desarrollado inicialmente por Tukey (1977), se conoce hoy por las siglas EDA (Exploratory Data Analysis). Incluye las medidas de la estadística descriptiva univariable (centralidad, variabilidad, asimetría, comprobación de los supuestos paramétricos...) y tiene por finalidad comprender, de forma individual, cada una de las variables.

- Análisis bivariable. Una vez analizada la idoneidad de las variables, y como paso previo a la mayoría de los análisis multivariables, resulta de gran utilidad identificar y conocer cómo se relacionan pares de variables. La matriz de correlaciones (en la que se muestra la interdependencia lineal entre las variables) a través del coeficiente de correlación de Pearson, será la que determine el grado de relación lineal entre dos variables aleatorias, a la vez que ofrece información sobre la variabilidad de una variable que queda explicada por la otra variable.

La última etapa del análisis exploratorio consiste en verificar si los datos cumplen los supuestos inherentes a las técnicas estadísticas empleadas. En este caso hemos hecho la comprobación de homocedasticidad o igualdad de varianzas, de normalidad, de existencia de relaciones lineales entre variables y de ausencia de multicolinealidad. Todo el análisis estadístico se hizo utilizando el software spss. 
Por su parte, hemos de advertir que, en ocasiones, el abuso de los métodos señalados para reducir a la mínima expresión los indicadores a través de la formación de un "factor" o "componente" altamente representativo de la varianza, ha llevado a una mala práctica. El grupo de trabajo adoptó, como criterio de partida, reducir la dimensionalidad solo en los casos de correlación significativa, manteniendo siempre la división en las cuatro categorías inicialmente definidas. De esta manera se pudo interpretar con mayor nitidez el significado de los factores resultantes.

En síntesis, el procedimiento se estructuró en cuatro fases:

a. Tipificación de variables y reducción de la dimensionalidad por cada grupo o categoría de indicadores mediante componentes principales.

b. Reducción de la dimensionalidad de los factores temáticos anteriores y asociación temática.

c. Sumatoria lineal de factores resultantes identificando vulnerabilidades en valores n Std. Dev. (standard deviation) sobre la media.

d. Precisión de delimitaciones a partir de indicadores de contraste y criterios de homogeneidad morfológica.

\section{Tipificación y reducción de la dimensionalidad}

El primer paso dado en este proceso consistió en la tipificación de las variables para hacer los índices agregables. Para ello, a los registros de las variables expresados en diferentes unidades de medida, se les aplicó una fórmula de estandarización y se corrigió, en el caso de que fuese necesario, el sentido de las variables para garantizar su adecuada adición lineal. No se trata de una cuestión baladí; la transformación o tipificación de variables, junto con la cuestión de la ponderación, constituyen dos de los inconvenientes principales a la hora de formar índices sintéticos.

Luego, a partir de la intuición inicial de comportamientos relacionados, se seleccionaron los indicadores sintomáticos agrupándolos de la siguiente forma, con el objetivo de valorar su correlación:

A. Temática de Indicadores sociodemográficos

A2. Población envejecida y A8. Hogares envejecidos.

A6. Paro registrado y A5. Población sin estudios.

Se mantiene como indicador sintomático independiente A4. Proporción de inmigrantes extranjeros.

B. Temática de Indicadores activad económica

Se mantiene como único indicador sintomático independiente el B6. Estratificación socioeconómica.

C. Temática de Indicadores caracteristicas residenciales

C10. Falta de calidad aparente según Catastro; C12. Falta de accesibilidad de la edificación; C5. Dimensión media de la vivienda; y C8. Valor medio de la superficie construida de uso residencial. 


\section{Temática de Indicadores características urbanas}

Todos los indicadores de esta temática se considerarán como descriptivos y no sintomáticos, por lo que no se hará ninguna reducción de su dimensionalidad.

De forma resumida, en esta primera fase del trabajo se sacaron las siguientes conclusiones:

- La correlación entre los indicadores A2. Población envejecida y A8. Hogares envejecidos es alta $(\mathrm{r}=0,58)$ y se determinó un único factor representativo del 79 por ciento de la varianza, que denominamos "Senectud" y que se interpretaba como: cuanto más envejecida está la población, mayor número de hogares vulnerables encontramos.

- Con respecto a los indicadores A5. Población sin estudios y A6. Paro registrado, se comprobó la correlación directa entre ambos $(\mathrm{r}=0,80)$ y se decidió despejar un único factor representativo del 90 por ciento de la varianza, que denominamos "Problemas laborales", cuya interpretación fue: cuanto menor formación de la población, mayor proporción de paro.

- Por otro lado, se trató de buscar la estructura subyacente de estas variables, que daría cuenta de la depreciación por obsolescencia funcional de las viviendas debido a la falta de accesibilidad, dimensión de los pisos y falta de calidad aparente. Para esto se comprobó la relación entre: C10. Falta de calidad aparente según Catastro; C12. Falta de accesibilidad de la edificación; C5. Dimensión media de la vivienda; y C8. Valor medio de la superficie construida de uso residencial. Las correlaciones comprobadas en este caso estuvieron comprendidas entre 0,31 y 0,52 y se usó un único factor que se interpretó como: cuanto peor la calidad y falta de accesibilidad, y menor dimensión media de las viviendas, menor es su valor medio por metro cuadrado construido.

- Los factores anteriores, junto con los indicadores A4. Proporción de inmigrantes extranjeros; y B6. Estratificación socioeconómica, que se mantienen sin correlacionar, constituyen la primera fase de reducción de dimensionalidad del estudio (Cuadro 3).

CUADro 3 | Resumen de reducción de la dimensionalidad (1 ${ }^{\text {a }}$ Fase)

\begin{tabular}{|l|l|}
\hline \multicolumn{1}{|c|}{ INDICADORES } & \multicolumn{1}{c|}{ FACTORES } \\
\hline A2. Población envejecida + A8. Hogares envejecidos & Senectud \\
\hline A5. Población sin estudios + A6. Paro registrado & Problemas laborales \\
\hline A4. Proporción de inmigrantes extranjeros & Inmigración \\
\hline B6. Estratificación socioeconómica & Estratificación socioeconómica \\
\hline $\begin{array}{l}\text { C10. Falta de calidad aparente según Catastro; C12. Falta de } \\
\text { accesibilidad de la edificación; C5. Dimensión media de la } \\
\text { vivienda; y C8. Valor medio de la superficie construida de uso } \\
\text { residencial }\end{array}$ & $\begin{array}{l}\text { Depreciación por obsolescencia } \\
\text { funcional }\end{array}$ \\
\hline
\end{tabular}

FUENTE ELABORACIÓN PROPIA 
Reducción de la dimensionalidad de los factores anteriores y asociación temática Con los datos anteriores, se comprueba la correlación existente entre los factores "Problemas laborales" y "Estratificación socioeconómica", con la finalidad de reducirlos a un único factor. Como era previsible, la correlación obtenida es muy alta $(\mathrm{r}=-0,86)$ y de sentido negativo, lo cual indica la relación inversa entre las dos variables analizadas. La interpretación del factor sintético obtenido puede describirse como: cuanto mayor es el estatus social de la zona, menores son los problemas laborales y formativos. Como se puede observar en el Cuadro 4, comparándolo con el Cuadro 3, se ha ańadido una tercera columna denominada Tipo de Vulnerabilidad, en la que se ha establecido la denominación de la temática de vulnerabilidad representada por cada factor.

\section{CUADRo 4 Resumen de Reducción de la dimensionalidad de los factores temáticos (2a Fase)}

\begin{tabular}{|l|l|l|}
\hline \multicolumn{1}{|c|}{ INDICADORES } & \multicolumn{1}{|c|}{ FACTORES } & \multicolumn{1}{|c|}{ TIPO DE VULNERABILIDAD } \\
\hline $\begin{array}{l}\text { A2. Población envejecida + } \\
\text { A8. Hogares envejecidos }\end{array}$ & Senectud & $\begin{array}{l}\text { Vulnerabilidad por } \\
\text { envejecimiento }\end{array}$ \\
\hline A4. Proporción de inmigrantes extranjeros & Inmigración & Vulnerabilidad por integración \\
\hline $\begin{array}{l}\text { Factor "Problemas Laborales" + } \\
\text { B6. Estratificación socioeconómica }\end{array}$ & Déficit según estatus & Vulnerabilidad económica \\
\hline $\begin{array}{l}\text { C10. Falta de calidad aparente según } \\
\text { Catastro; C12. Falta de accesibilidad de la } \\
\text { edificación; C5. Dimensión media de la } \\
\text { vivienda; y C8. Valor medio de la superficie } \\
\text { construida de uso residencial }\end{array}$ & $\begin{array}{l}\text { Depreciación por } \\
\text { obsolescencia funcional }\end{array}$ & Vulnerabilidad residencial \\
\hline
\end{tabular}

FUENTE ELABORACIÓN PROPIA

Establecimiento de umbrales para la determinación de secciones censales vulnerables

En trabajos de esta naturaleza, con frecuencia suele ser una decisión especialmente comprometida el establecimiento de umbrales para la determinación de los ámbitos críticos respecto a la vulnerabilidad. Normalmente, el punto a partir del cual se fija el umbral de riesgo es una decisión que se debe tomar sobre la base de la contextualización de los datos respecto al universo analizado y comparado con otras realidades urbanas de referencia. Los criterios habitualmente más empleados para determinar dichos umbrales de riesgo pueden resumirse en tres:

a. Cortes naturales o de Jenks derivados de la propia estructura interna de los datos.

b. Umbrales determinados a partir de $n$ veces la media aritmética municipal de la variable.

c. Umbrales determinados a partir de $n$ veces la desviación típica de la variable respecto a la media municipal.

En nuestro caso, consideramos la opción $c$ como la más adecuada para clasificar todos los datos, ya que la distancia ofrecida por $n$ desviaciones típicas responde 
consecuentemente a la naturaleza de cada variable. Para trabajar con este criterio hicimos varias aproximaciones orientadas a decidir el valor $n$ de las desviaciones, determinando finalmente que la más adecuada era 1 desviación típica.

Determinación de las tipologías de vulnerabilidad identificables

Una vez conocidas las temáticas de la vulnerabilidad identificadas en el estudio (vulnerabilidad por envejecimiento, vulnerabilidad por integración, vulnerabilidad económica y vulnerabilidad residencial), y determinado el rango a partir del cual se considera alcanzado el nivel crítico en cada uno de ellos, se procedió a valorar las posibles combinaciones, estableciendo una distinción tipológica para cada uno de los casos:

Monovulnerabilidad. Se detecta en aquellas secciones censales en las que solo se identifica un tipo de vulnerabilidad. En este caso tenemos los siguientes tipos (Cuadro 5):

- Vulnerabilidad social (por envejecimiento o por integración)

- Vulnerabilidad económica

- Vulnerabilidad residencial

CUADro 5 | Tipologías de vulnerabilidad (n=1 desv. Tip)

\begin{tabular}{|c|c|c|c|}
\hline & TIPOLOGÍAS DE VULNERABILIDAD & $\begin{array}{l}\mathrm{N}^{\mathbf{o}} \text { SECCIONES } \\
\text { CENSALES }\end{array}$ & $\begin{array}{c}\text { \% RESPECTO } \\
\text { AL TOTAL }\end{array}$ \\
\hline \multirow{3}{*}{ MONOVULNERABILIDAD } & $\begin{array}{l}\text { Vulnerabilidad social (por envejecimiento o } \\
\text { por integración) }\end{array}$ & 378 & 15,70 \\
\hline & Vulnerabilidad económica & 157 & 6,50 \\
\hline & Vulnerabilidad residencial & 92 & 3,80 \\
\hline \multirow{3}{*}{ POLIVULNERABILIDADES } & Vulnerabilidad residencial + económica & 63 & 2,25 \\
\hline & Vulnerabilidad económica + social & 57 & 2,60 \\
\hline & Vulnerabilidad social + residencial & 175 & 7,30 \\
\hline $\begin{array}{l}\text { VULNERABILIDAD } \\
\text { INTEGRAL }\end{array}$ & $\begin{array}{l}\text { Vulnerabilidad integral (social + } \\
\text { económica + residencial) }\end{array}$ & 102 & 4,25 \\
\hline \multicolumn{2}{|l|}{ TOTAL } & 1.024 & 42,70 \\
\hline
\end{tabular}

FUENTE ELABORACIÓN PROPIA

Polivulnerabilidad. Se detecta en aquellas secciones censales en las que es posible identificar dos tipos de vulnerabilidad simultáneamente. En este caso tenemos los siguientes tipos:

- Vulnerabilidad residencial + económica

- Vulnerabilidad económica + social

- Vulnerabilidad social + residencial

Vulnerabilidad integral. Se detecta en aquellas secciones censales en las que es posible identificar tres tipos de vulnerabilidad simultáneamente. En este caso tenemos:

- Vulnerabilidad integral (social + económica + residencial) 
En el Cuadro 6 se hace un resumen más detallado de la polivulnerabilidad y de la vulnerabilidad integral.

\begin{tabular}{|c|c|c|c|}
\hline & $\begin{array}{l}\text { VULNERABILIDAD INTEGRAL + } \\
\text { POLIVULNERABILIDADES }\end{array}$ & $\begin{array}{l}N^{\circ} \text { SECCIONES } \\
\text { CENSALES }\end{array}$ & $\begin{array}{c}\text { \% RESPECTO AL } \\
\text { TOTAL }\end{array}$ \\
\hline \multirow{3}{*}{ DELIMITACIÓN ESTRICTA } & No de secciones censales afectadas & 397 & 16,50 \\
\hline & No de habitantes afectados & 518.057 hab. & 15,80 \\
\hline & Superficie afectada & 1.668 ha* $^{*}$ & 2,70 \\
\hline \multirow{4}{*}{$\begin{array}{l}\text { REDELIMITACIÓN CON } \\
\text { CRITERIOS MORFOLÓGICOS }\end{array}$} & No de secciones censales afectadas & 620 & 25,80 \\
\hline & No de habitantes afectados & 799.382 hab. & 24,40 \\
\hline & Superficie afectada & 2.300 ha & 3,80 \\
\hline & No de recintos redelimitados & 145 & \\
\hline
\end{tabular}

FUENTE ELABORACIÓN PROPIA

* La superficie de 1.668 ha se calcula no teniendo en cuenta el área de la sección 18045 situada en el Distrito Villa de Vallecas, debido a su gran extensión y escasa representatividad.

\section{Delimitación de ámbitos vulnerables}

Tras identificar las distintas tipologías de vulnerabilidad sobre las secciones censales del municipio de Madrid, se procedió a establecer una redelimitación coherente que supera los contornos iniciales propios de las secciones censales hasta ahora útiles. Para ello se procedió según se indica en la Figura 2.

- Las delimitaciones partirán de áreas donde exista una o varias secciones censales polivulnerables o con vulnerabilidad integral (Cuadro 6).

- La monovulnerabilidad solo se empleará como referencia para establecer la delimitación más coherente de la zona.

- Se contextualizará la redelimitación de las áreas definitivas atendiendo a los indicadores de vulnerabilidad denominados como descriptivos en este trabajo.

- Se utilizará la relación de los diferentes "sectores urbanos" delimitados por la Comunidad de Madrid para el municipio de Madrid. Se entiende por sector urbano una porción diferenciada de un núcleo que cuenta con una tipología de época o construcción similar, o es conocida y nombrada de una manera particular por cualquier otra causa ${ }^{12}$. Los sectores urbanos permiten ajustar las delimitaciones atendiendo a la morfología de cada zona.

12 Se trata de un trabajo especialmente interesante y muy útil para el análisis urbano, realizado por el Instituto de Estadística de la Comunidad de Madrid, que permite trabajar con una unidad morfológica entre la sección censal y las delimitaciones de barrios. 
- Se emplearán las delimitaciones de polígonos de bloque abierto y Norma Zonal $3.1^{13}$ del trabajo "Análisis de los polígonos de bloque abierto" (Dirección General de Planeamiento, 2007).

FIGURA 2 Síntesis de redelimitación de áreas vulnerables (polivulnerables e integrales)

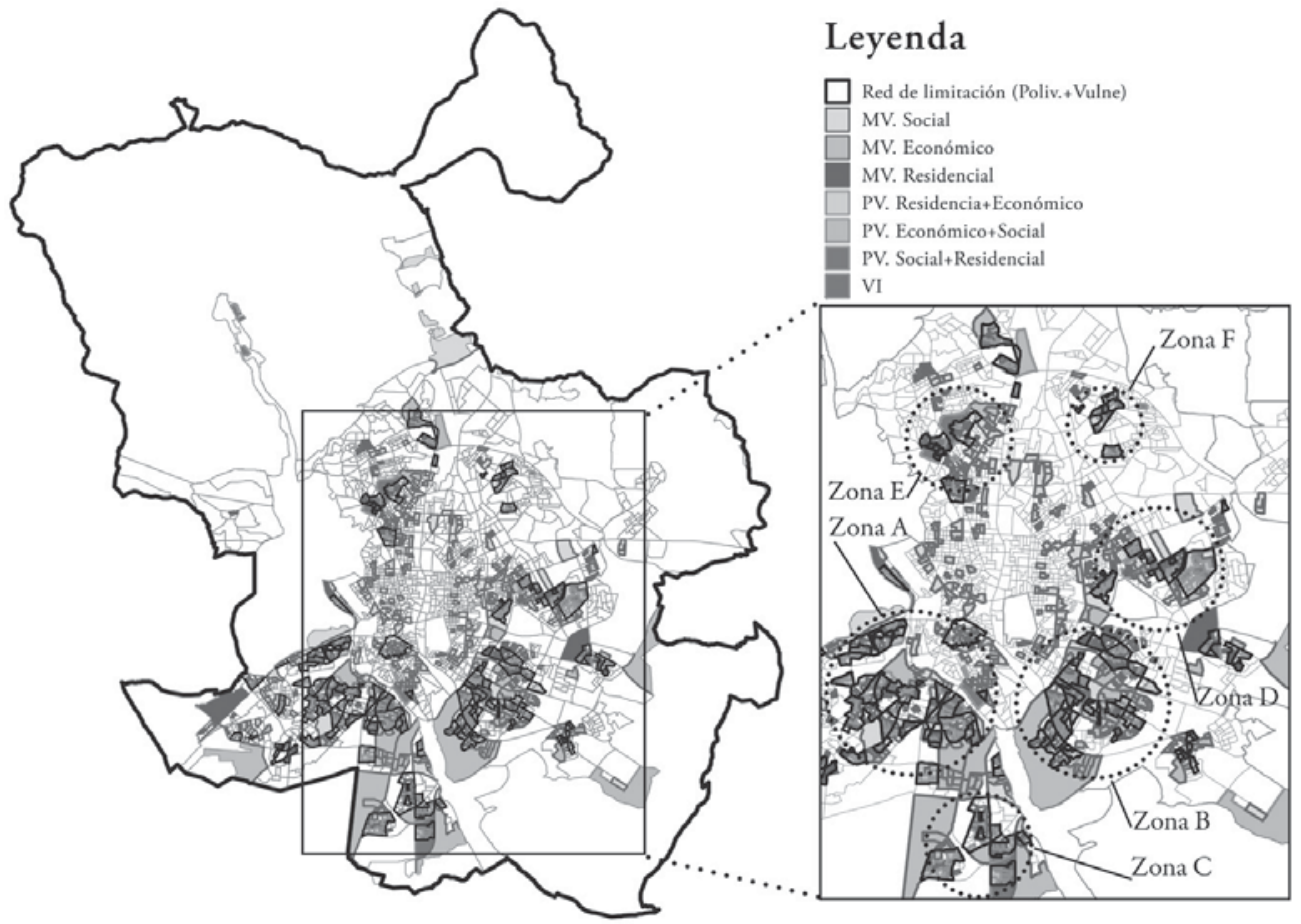

FUENTE ELABORACIÓN PROPIA

\section{Resultados obtenidos y comparación con otros trabajos de naturaleza similar}

\section{Resultados obtenidos}

Como resultado del análisis, hemos obtenido la identificación de 145 recintos que afectan al 25 por ciento de la población de Madrid, señalando que al menos en 19 de ellos la situación de vulnerabilidad integral es especialmente significativa ${ }^{14}$, lo que sitúa estos ámbitos como prioritarios (Figura 3 y Cuadro 6).

13 Norma Zonal del Plan General de Ordenación Urbana (PGOU) de 1985, que recoge la mayor parte de los grupos de vivienda de promoción unitaria de las décadas de los sesenta-setenta.

14 Consideramos la vulnerabilidad especialmente significativa en aquellas redelimitaciones donde al menos dos secciones censales queden destacadas con "vulnerabilidad integral". 


\section{Figura 3 | Prioridad de actuación en Áreas Vulnerables}

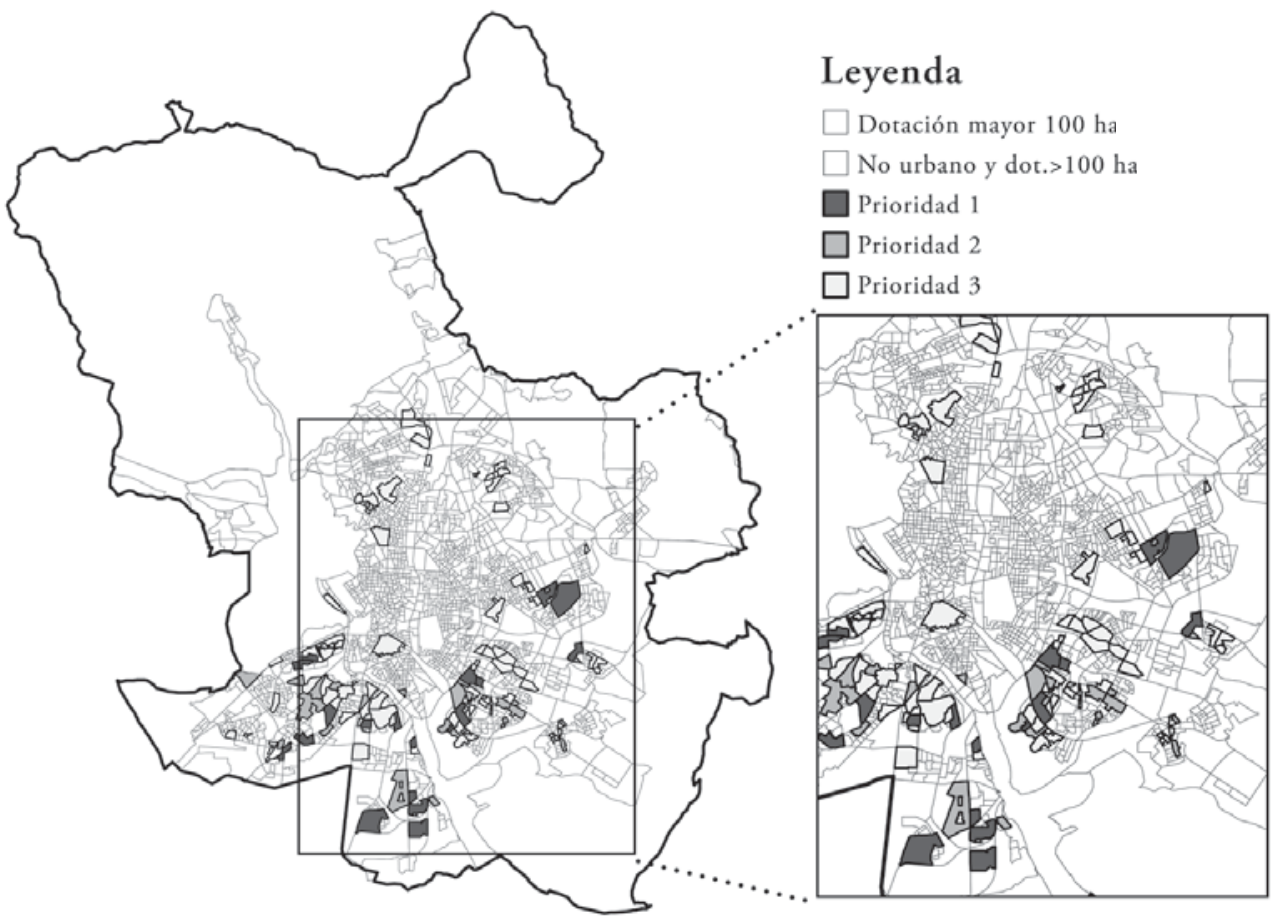

FUENTE ELABORACIÓN PROPIA

\section{Comparación con otras delimitaciones de similar naturaleza}

Los resultados de este trabajo han sido comparados con los de otros de similares contenidos, centrados también en el municipio de Madrid. Las conclusiones que extraemos de dicha comparación pueden exponerse, de manera resumida, como sigue:

Delimitación de las ARI (Áreas de Rehabilitación Integral) y las ZRI (Zonas de Rehabilitación Integral) ${ }^{15}$

Existe prácticamente un 50 por ciento de coincidencia entre los recintos delimitados en las ARI y las zRI, y los nuestros. Si no tenemos en cuenta las delimitaciones situadas en el distrito Centro, que atienden fundamentalmente a criterios de conservación histórica y patrimonial, la coincidencia es del 61 por ciento. Por su parte, casi el 20 por ciento de los recintos vulnerables deducidos en nuestro trabajo ya tienen algún tipo de plan de rehabilitación que actúa sobre ellos.

Delimitaciones del "Estudio sobre barrios desfavorecidos de Madrid", realizado para la Federación Regional de Asociaciones de Vecinos de Madrid (FRAVM), (Pérez, 2007). En este trabajo, la fuente estadística de partida ha sido el Censo de Población y Viviendas de 2001, que supone una representación poco fiable de la situación actual. Además, entre los indicadores empleados para determinar las áreas poliproblemáticas se ha utilizado el de "Percepción de la delincuencia", que supone un dato subjetivo, ya que constituye la sensación del residente y no una constatación 
de hechos en función de denuncias, incidentes, etcétera. Esto dibuja un panorama muy generalizado que redunda en una delimitación excesivamente generosa de la realidad. Con todo, el 60 por ciento de las áreas identificadas en nuestro trabajo también lo son de la FRAVM.

Delimitaciones del estudio encargado por el Ministerio de Fomento, "Análisis urbanistico de barrios desfavorecidos de España" (Ministerio de Fomento \& Instituto Juan de Herrera, 2010), dirigido por el Prof. A. Hernández Aja.

Igual que en el caso anterior, este estudio de carácter sistemático, encargado para un número considerable de ciudades del país, ha tenido que recurrir al uso de fuentes homogéneas y fácilmente disponibles. Tal circunstancia ha supuesto una servidumbre importante en los datos de partida, ya que el análisis bebe fundamentalmente del Censo de 2001 actualizado en algunos datos a partir del Padrón de Habitantes de 2006. Aun con todo, si comparamos la delimitación de "Barrios desfavorecidos" con las propuestas en nuestro trabajo, podemos constatar un 71,2 por ciento de coincidencias.

Delimitaciones del estudio "Exclusión residencial en el municipio de Madrid", encargado por la Empresa Municipal de Vivienda y Suelo (EMVS) de Madrid (Antón et al., 2008).

En este trabajo se utiliza nuevamente como base estadística el Censo de 2001, por lo que todo lo dicho anteriormente en referencia a la escasa representatividad de los datos es también aplicable aquí. Los criterios de delimitación de los ámbitos de exclusión son más restrictivos que los empleados en nuestro trabajo, al usarse un 1,5 de la desviación típica. Con todo ello, el porcentaje de coincidencia entre los dos estudios es de un 56 por ciento.

\section{Conclusiones finales}

A la luz de los resultados de este trabajo, se pueden sacar algunas conclusiones respecto a las áreas vulnerables de Madrid, y otras que suponen una reflexión más amplia a propósito de la intervención en estas zonas:

- El 80 por ciento de los casos delimitados se encuentra situado fuera de la "almendra central" de Madrid. A su vez, es evidente la ubicación de los recintos en el sur, a partir de la denominada línea de pobreza.

- Los escenarios básicos caracterizados como zonas vulnerables son, en la mayor parte de los casos, barrios de polígonos de bloque abierto, identificados en Madrid particularmente con las Normas Zonales 3.1.a y 3.2, construidos entre las décadas de los sesenta y los setenta. También son destacables los casos de las Colonias históricas.

- Podemos decir, en cifras generales, que en los 145 recintos redelimitados reside un cuarto de la población de la capital y que la superficie afectada por dichas zonas abarca unas 2.000 hectáreas, algo así como el distrito de San Blas.

- Con este trabajo, el Área de Gobierno de Urbanismo y Vivienda cuenta con un estudio basado en indicadores actualizados, que de forma sistemática permite 
dar una primera aproximación a la magnitud de la vulnerabilidad en la ciudad. Dicho análisis cumple con las exigencias establecidas en el art. 48 del Capítulo III. Eje 3: Áreas de rehabilitación integral y renovación urbana. Sección 1 y 2 del Plan de Viviendas 2009-12, en referencia a los requisitos solicitados a la Memoria - Programa para la Áreas de Rehabilitación Integral (ARIs), así como para Áreas de Renovación Urbanas (ARUS). OEURE

\section{Referencias bibliográficas}

Alguacil, J. (2006). Barrios desfavorecidos: Diagnóstico de la situación española. En F. Vidal Fernández (Ed.), V Informe FUHEM de políticas sociales: La exclusión social y el estado del bienestar en España (pp. 155-168). Madrid: FUHEM.

Alguacil, J. (2011, junio). Sobre la vulnerabilidad urbana. Presentación en Jornada La vulnerabilidad urbana en España: Instrumentos para el análisis y politicas para la acción / Foro de Debates: Ciudad y Territorio. Simposio realizado en la Secretaría de Estado de Vivienda y Actuaciones Urbanas del Ministerio de Fomento, Madrid, 30 de junio de 2011.

Antón, F.; Cortés, L.; Martínez, C. \& Navarrete, J. (2008). La exclusión residencial en España. En A. Arriba González (Ed.), Politicas y bienes sociales. Procesos de vulnerabilidad y exclusión social (pp. 219-229). Madrid: Fundación foessa (Fomento de Estudios Sociales y de Sociología Aplicada).

Arias, F. (Coord.). (2000). Las desigualdad urbana en España. Madrid: Ministerio de Fomento, Dirección General de Programación Económica y Presupuestaria, Centro de Publicaciones.

Arriagada, C. \& Rodríguez, J. (2003). Segregación residencial en áreas metropolitanas de América Latina: magnitud, características, evolución e implicaciones de política. Serie Población y Desarrollo 47. Santiago de Chile: Comisión Económica para América Latina y el Caribe (Cepal). En http://bit.ly/15Jfsq7

Beck, U. (1998). Democracy without enemies. Cambridge, Ma: Polity Press.

Bisquerra, R. (1989). Introducción conceptual al análisis multivariable. Un enfoque informático con los paquetes SPSS-X; BMDP, LISREL, y SPAD (Vol. 1-2). Barcelona: Promociones y Publicaciones Universitarias.

Bruquetas, M.; Moreno, F. J. \& Walliser, A. (2005). La regeneración de barrios desfavorecidos (Documento de trabajo 67). Madrid: Fundación Alternativas. En http://bit.ly/193no6x

Bustamante, J. (2000). Un marco de referencia acerca de la vulnerabilidad de los migrantes como sujetos de los derechos humanos. Documento presentado en Taller sobre mejores prácticas en materia de migración. Santiago de Chile, Comisión Económica para América Latina y el Caribe (Cepal).

Castells, M. (1991). El auge de la ciudad dual: Teoría social y tendencias sociales. Alfoz, 90, $89-102$.

Conway, M. \& Konvitz, J. (2000). Meeting the challenge of distressed urban areas. Urban Studies, 37(4), 749-774. doi: 10.1080/00420980050004008

Cortés, L. (1997). Hablando de la exclusión residencial. Madrid: Caritas. 
De Miguel, A. (1967). Primer estudio de indicadores sociales. En A. de Miguel, J. Diez \& A. Medina (Eds.), Tres estudios para un sistema de indicadores sociales (pp. 11-90). Madrid: Euramérica.

De Miguel, J. \& Sevilla-Guzmán, E. (1973). Tipos de índices en Sociología. Revista de Estudios Sociales, 8, 139-160.

Egea, C.; Nieto, J. A.; Domínguez, J. \& González, R. (2008). Vulnerabilidad del tejido social de los barrios desfavorecidos en Andalucía. Análisis y potencialidades. Sevilla: Centro de Estudios Andaluces, Consejería de la Presidencia, Junta de Andalucía. En http://bit. ly/1 $\mathrm{f0yI} 5 \mathrm{H}$

Ffrench-Davis, R. (1999). Macroeconomía, comercio y finanzas para reformar las reformas en América Latina. Santiago de Chile: McGraw-Hill Interamericana.

Galster, G. \& Killen, S. (1995). The geography of opportunity: A reconnaissance and conceptual framework. Housing Policy Debate, 6(1), 7-43. doi: 10.1080/10511482.1995.9521180

Hernández Aja, A. (2007, julio/agosto). Áreas vulnerables en el centro de Madrid. Cuadernos de Investigación Urbanistica, 53, 1-102. En http://polired.upm.es/index.php/ciur/article/ view/268/263

Keestelot, C. (2008, marzo). Urban socio-spatial configurations and the future of European cities. En Y. Kazepov (Ed.), Cities of Europe: Changing contexts, local arrangements, and the challenge to urban cohesion (pp. 123-148). Oxford: Blackwell Publishing.

Kaztman, R.; Beccaria, L.; Filgueira, F.; Gobert \& L. Kessler, G. (1999). Vulnerabilidad, activos y exclusión social en Argentina y Uruguay (Reporte No. 107). Recuperado de Organización Internacional del Trabajo: http://www.oit.org.pe/wDMs/bib/publ/doctrab/ dt_107.pdf

King, G.; Keohane, R. \& Verba, S. (2000). El diseño de la investigación social. La inferencia cientifica en los estudios cualitativos. Madrid: Alianza Editorial.

Leal, J. (2002). Segregación social y mercados de vivienda en las grandes ciudades. RES: Revista Española de Sociología, 2, 59-75. En http://www.fes-web.org/uploads/files/res/ res02/04.pdf

López de Lucio, R. (2008). Hacia los procesos integrales de rehabilitación urbana. En R. López de Lucio (Coord.), PROGRESDEC/ESDP steps Interreg III C Zona Sur Operación Marco Regional (pp. 286-349). Madrid: Consejería de Medio Ambiente y Ordenación del Territorio.

Márquez, R. (2006). El diseño de indices sintéticos a partir de datos secundarios en metodologías y estrategias para el análisis social. Santiago de Chile: LOM Ediciones.

Mayeur, C. (1998). Condiciones residenciales e integración de los inmigrantes: problemas residenciales de los inmigrantes y definición de las políticas de actuación pública. En J. Leal \& C. Mayeur (Eds.), Vivienda e integración social de los inmigrantes (pp. 125-141). Madrid: Ministerio de Trabajo y Asuntos Sociales.

Molinatti, F. (2013). Segregación residencial e inserción laboral en la ciudad de Córdoba. EURE, 39(117), 117-145. doi: 10.4067/S0250-71612013000200006

Montoliu, E. (2008). La línea de la pobreza del municipio de Madrid. Madrid: Departamento de Datos Estadísticos del Ayuntamiento de Madrid.

Moser, C. \& Van Bronkhorst, B. (1999). Youth violence in Latin America and the Caribbean: Costs, causes and interventions (The World Bank, Report No. 19816). Recuperado de The World Bank, http://bit.ly/GzHYP5 
Pérez, V. (2007). Estudio sobre barrios desfavorecidos de Madrid. Madrid: Federación Regional de Asociaciones de Vecinos de Madrid.

Pizarro, R. (2001). La vulnerabilidad social y sus desafíos: una mirada desde América Latina. Serie Estudios Estadísticos y Prospectivos 6. Santiago de Chile: Comisión Económica para América Latina (Cepal), http://www.eclac.org/publicaciones/xml/3/6553/lcl1490e.pdf

Rodríguez, J. (2001). Vulnerabilidad y grupos vulnerables: un marco de referencia conceptual mirando a los jóvenes. Serie Población y Desarrollo 17. Santiago de Chile: Comisión Económica para América Latina (Cepal), http://www.eclac.org/publicaciones/ xml/9/7889/lcl1588-P.pdf

Rodríguez, J. (2008, diciembre). Movilidad cotidiana, desigualdad social y segregación residencial en cuatro metrópolis de América Latina. EURE, 34(103), 49-71. doi: 10.4067/ S0250-71612008000300003

Rodríguez, J. \& Arriagada, C. (2004, mayo). Segregación residencial en la ciudad latinoamericana. EURE, 30(89), 5-24. doi: 10.4067/S0250-71612004008900001

Sabatini, F.; Cáceres, G. \& Cerda, J. (2001, diciembre). Segregación residencial en las principales ciudades chilenas: tendencias de las tres últimas décadas y posibles cursos de acción. EURE, 27(82), 21-42. doi: 10.4067/S0250-71612001008200002

Subirats, J. \& Gomà, R. (2003). Un paso más hacia la inclusión social. Generación de conocimiento, políticas y prácticas para la inclusión social. Madrid: Acción Social.

Temes, R. (2007). El tapiz de Penélope. Transformaciones residenciales sobre tejidos sin valor patrimonial (Tesis doctoral, Universidad Politécnica de Valencia, Valencia, España). Recuperada de http://hdl.handle.net/10251/2906

Tukey, J. W. (1977). Exploratory Data Analysis. Reading, MA: Addison-Wesley.

\section{Documentos oficiales}

Ayuntamiento de Madrid (2011). La población extranjera en la ciudad de Madrid. Dossier de magnitudes básicas 2011 [s.n]. Madrid: Autor. En http://bit.ly/1fuQEqe

Comisión Económica para América Latina y el Caribe (2000). Panorama social de América Latina 1999-2000 [s.n]. Santiago de Chile: Autor. En http://bit.ly/193xaFJ

Dirección General de Planeamiento Urbanístico (2007). Análisis de Polígonos de Bloque Abierto. Programa Municipal de Actuaciones para la Periferia de Madrid [s.n]. Madrid: Autor.

Dirección General de Vivienda, Arquitectura y Urbanismo, Junta de Castilla y León, España (2012). Plan de Rehabilitación Integral de Castilla y León. Valladolid: Autor. En http:// www.jcyl.es/junta/cf/20120209_PRICyL.pdf

Generalidad de Cataluña (2004). Ley 2/2004, de 4 de junio, de mejora de barrios, áreas urbanas y villas que requieren una atención especial. En http://www.todalaley.com/mostrarLey1391p1 tn.htm

Gobierno Vasco, Departamento de Hacienda y Administración Pública, España (2001). Programa Izartu I y II (Politica de Cohesión Territorial en la Comunidad Autónoma del País Vasco, 2001-2005 / 2004-2008). En http://bit.ly/19QSpH6

Gobierno Vasco, Departamento de Hacienda y Administración Pública, España (2000). Decreto 236/2000, de 28 de noviembre, por el que se establecen medidas de apoyo a actuaciones integrales de revitalización urbana en la Comunidad Autónoma del País Vasco. En http://bit.ly/19QZ3Nv 
Instituto Nacional de Estadística, España (2001). Censo de Población y Viviendas 2001. En http://bit.ly/1fDr3eF

Junta Electoral Central, España (2012). Ley Orgánica 5/1985, de 19 de junio, del Régimen Electoral General. En http://bit.ly/nOjhYP.

Ministerio de Fomento, España (s/f.). Observatorio de la vulnerabilidad urbana. En http://bit. ly/1dOjDkx

Ministerio de Fomento \& Instituto Juan de Herrera - Escuela Técnica Superior de Arquitectura de Madrid, España (2010). Análisis urbanistico de barrios vulnerables en España. Sobre la vulnerabilidad urbana. Estudio dirigido por el Prof. Agustín Hernández Aja. Madrid: Autores. En http://bit.ly/18lfgeB

Ministerio de Vivienda y Urbanismo, Chile (2012). Programa de Recuperación de Barrios. En http://www.minvu.cl/opensite_20070212164909.aspx

Moreno, A. (Coord.). (2003). La distribución espacial de la renta en la Comunidad de Madrid. Análisis y aplicaciones. Madrid: Instituto de Estadística de la Comunidad de Madrid. En http://www.madrid.org/iestadis/gazeta/publicaciones/iesparentano.htm

Organización de las Naciones Unidas (2004). Informe sobre la situación social en el mundo 2003. Vulnerabilidad social: Fuentes y desafios. Nueva York: United Nations, Department of Economic and Social Affairs.

Parlamento de Cataluña (2004). Ley de Mejora de barrios, áreas urbanas y villas que requieren una atención especial de Cataluña. Ley 2/2004, de 4 junio. En http://bit.ly/1fDeX5i

République Française (1995). Loi 95-115 du 4 février 1995 d'orientation pour l'aménagement et le développement du territoire (Ley 95-115 del 4 de febrero de 1995, proporciona directrices para la ordenación y el desarrollo territorial). En http://bit.ly/GzshZ3 